\title{
MOLECULAR TAXONOMY OF SOME SPONGES (Demospongiae) USING RIBOSOMAL (18S rRNA) AND PARTIAL MITOCHONDRIAL (COI) GENES
}

\author{
Ton That Huu Dat ${ }^{1 *}$, Nguyen Thi Kim Cuc ${ }^{2}$, Pham Viet Cuong ${ }^{1}$ \\ ${ }^{1}$ Mien Trung Institute for Scientific Research, VAST \\ ${ }^{2}$ Institute of Marine Biochemistry, VAST
}

\begin{abstract}
Sponges, the most ancient multicellular metazoan, were widely distributed across habitats. Vietnam is known to possess a high biodiversity of sponges, however, they are mostly identified based on morphological characteristics and lack the molecular data. In the current study, the phylogenetic relationship of some sponges (Demospongiae) in Vietnam was constructed using two independent markers (COI and 18S rRNA). In this paper the individual markers (COI and 18S rRNA) were successfully used to identify some sponge taxa at the species level. The obtained results showed the congruence of molecular taxonomy using two independent markers. However, our study showed that a combination of the two markers provided more information and supported better for sponge identification. At order level, the COI tree and 18S rRNA tree also recovered the same clades, indicating the congruence of COI and 18S rRNA genes in sponge classification. However, branching order of the clades in COI tree was weakly supported and slightly different from those in $18 \mathrm{~S}$ rRNA tree.
\end{abstract}

Keywords: Demospongiae, 18S rRNA, COI, Phylogenetic tree, Porifera; Mitochondrial genes.

Citation: Ton That Huu Dat, Nguyen Thi Kim Cuc, Pham Viet Cuong, 2018. Molecular taxonomy of some sponges (demospongiae) using ribosomal (18S RRNA) and partial mitochondrial (COI) genes. Academia Journal of Biology, 40(4): 67-75. https://doi.org/10.15625/2615-9023/v40n4.12705.

*Corresponding author email: huudat96@gmail.com

Received 26 June 2018, accepted December 2018

\section{INTRODUCTION}

Sponges (phylum Porifera) are the most simple and ancient metazoan. The sponges were appeared on Earth since at least 650 million years ago (Maloof et al., 2010), and widely distributed across geographical and bathymetrical habitats (Bell, 2008). At least 8.500 valid species has been described in phylum Porifera belonging to four classes, 25 orders, 128 families, and 680 genera. The Demospongiae is known as the most morphologically diverse and one of the richest classses of the Porifera (> 85\% of total species number) (van Soest et al., 2012). Until now, sponge classification has been increasingly concerned of scientists due to many new species have not discovered. The number of known species was only a half of estimated number of species (van Soest et al., 2012).

Initially, the identification of sponges is based mainly on the traditional method using morphological characteristics (e.g., the skeletal structure, spicule, and external morphology), in which the skeletal and specular features are the most frequently used (Hooper \& Soest, 2002). However, the paucity and plasticity of morphological characters of sponge result in challenges of sponge identification and increase the cryptic and homoplasy speciation (van Soest et al., 2012). The introduction and development of molecular techniques have significantly contributed to our understanding of phylogenetic relationships and evolution of 
sponge systematics. Molecular data have provided new insights on the identification of sponge, particularly in some sponge taxa which morphological characters are few (Cárdenas et al., 2012).

In Vietnam up to now, at least 299 sponge species belonging to 124 genera, 65 families, 18 orders and 4 classes has, of which the Demospongiae occupied 281 species (94\% of the total of detected species) (Quang, 2013). However, most of these sponges were identified based on morphological characteristics. Therefore, the genetic variation and phylogenetic relationship of the sponge species still need to be done. In this study, we use two different phylogenetic markers (COI and 18S rRNA) to identify some Vietnamese demosponges and test the congruence of sponge identification based on independent markers.

\section{MATERIALS AND METHODS}

\section{Collection of sponge samples}

Sponge specimens were collected by SCUBA diving at Vinh Moc (Quang Tri), Lang Co (Thua Thien Hue) and Hon Mun (Nha Trang) (Table 1). Samples were stored in containers with seawater and kept at (-) $20^{\circ} \mathrm{C}$ for molecular analysis.

Table 1. Sponge samples in our study

\begin{tabular}{|c|c|c|c|c|c|c|}
\hline \multirow{2}{*}{ Code } & \multirow{2}{*}{ Taxon } & \multirow{2}{*}{ Date } & \multirow{2}{*}{ Site } & \multirow{2}{*}{ Coordinates } & \multicolumn{2}{|c|}{ Accession number } \\
\hline & & & & & 18S rRNA & COI \\
\hline MT1.2015 & $\begin{array}{c}\text { Amphimedon } \\
\text { compressa }\end{array}$ & Jan-2015 & Quang Tri & $\begin{array}{c}107^{\circ} 07^{\prime} 01.4^{\prime \prime E} \\
17^{\circ} 05^{\prime} 08.6^{\prime \prime} \mathrm{N}\end{array}$ & KY947243 & KY947259 \\
\hline MT2.2015 & $\begin{array}{c}\text { Xestospongia } \\
\text { testudinaria }\end{array}$ & Jan-2015 & Quang Tri & $\begin{array}{c}107^{\circ} 07^{\prime} 01.4^{\prime \prime E} \\
17^{\circ} 05^{\prime} 08.6^{\prime \prime N}\end{array}$ & KY947244 & KY947260 \\
\hline MT3.2015 & $\begin{array}{c}\text { Rhabdastrella } \\
\text { globostellata }\end{array}$ & Jan-2015 & Quang Tri & $\begin{array}{c}107^{\circ} 07^{\prime} 01.4^{\prime \prime} \mathrm{E} \\
17^{\circ} 05^{\prime} 08.6^{\prime \prime} \mathrm{N}\end{array}$ & KY947245 & KY947261 \\
\hline MT4. & $\begin{array}{c}\text { Rhabdastrella } \\
\text { globostellata }\end{array}$ & Jan-2015 & Quang Tri & $\begin{array}{c}107^{\circ} 07^{\prime} 01.4^{\prime \prime} \mathrm{E} \\
17^{\circ} 05^{\prime} 08.6^{\prime \prime} \mathrm{N}\end{array}$ & KY947246 & KY947262 \\
\hline MT5.2015 & Axos cliftoni & Jan & $\mathrm{Qu}$ & $\begin{array}{c}107^{\circ} 07^{\prime} 01.4^{\prime \prime} \mathrm{E} \\
17^{\circ} 05^{\prime} 08.6^{\prime \prime N}\end{array}$ & KY947247 & KY947263 \\
\hline MT6.2015 & Clathria reinwardti & Jan & $\mathrm{Qu}$ & $\begin{array}{l}.4 " \mathrm{E} \\
6 \mathrm{~N} \mathrm{~N}\end{array}$ & KY947248 & KY947264 \\
\hline MT7.2015 & $\begin{array}{c}\text { Amphimedon } \\
\text { compressa }\end{array}$ & Mar-2015 & Thua Thie & $\begin{array}{r}108^{\circ} 02 \\
16^{\circ} 19^{\prime}\end{array}$ & KY947249 & KY947265 \\
\hline MT8.2015 & Clathria reinwardti & Mar-2015 & Thua & $\begin{array}{l}5 \text { "E; } \\
.5 \mathrm{~N}\end{array}$ & KY947250 & KY947266 \\
\hline MT9.2015 & $\begin{array}{c}\text { Rhabdastrella } \\
\text { globostellata }\end{array}$ & Mar-2015 & Thua Thien Hue & $\begin{array}{l}5.9 " \mathrm{E} \\
.5 \mathrm{~N}\end{array}$ & KY947251 & KY947267 \\
\hline MT10.2015 & $\begin{array}{c}\text { Amphimedon } \\
\text { compressa }\end{array}$ & Mar-2015 & Thua Thien Hue & $\begin{array}{c}108^{\circ} 02^{\prime} 35.9^{\prime \prime} \mathrm{E} \\
16^{\circ} 19^{\prime} 58.5^{\prime \prime} \mathrm{N}\end{array}$ & KY947252 & KY947268 \\
\hline MT11.2015 & Clathria reinwardti & Mar & Thua Thien Hue & $\begin{array}{l}108^{\circ} 02^{\prime} 35.9^{\prime \prime} \mathrm{E} \\
16^{\circ} 19^{\prime} 58.5^{\prime \prime} \mathrm{N}\end{array}$ & KY947253 & KY947269 \\
\hline MT12.2015 & Tedania ignis & May-2015 & Nha Trang & $\begin{array}{l}109^{\circ} 15^{\prime} 05.6^{\prime \prime E} \\
12^{\circ} 10^{\prime} 35.4^{\prime \prime} \mathrm{N}\end{array}$ & KY947254 & KY947270 \\
\hline MT13.2015 & $\begin{array}{c}\text { Xestospongia } \\
\text { testudinaria }\end{array}$ & May-2015 & Nha Trang & $\begin{array}{l}109^{\circ} 15^{\prime} 05.6^{\prime \prime E} \\
12^{\circ} 10^{\prime} 35.4^{\prime \prime} \mathrm{N}\end{array}$ & KY947255 & KY947271 \\
\hline MT14.2015 & Tedania ignis & May-2015 & Nha Trang & $\begin{array}{l}109^{\circ} 15^{\prime} 05.6^{\prime \prime} \mathrm{E} \\
12^{\circ} 10^{\prime} 35.4^{\prime \prime} \mathrm{N}\end{array}$ & KY947256 & KY947272 \\
\hline MT15.2015 & $\begin{array}{c}\text { Xestospongia } \\
\text { testudinaria }\end{array}$ & May-2015 & Nha Trang & $\begin{array}{c}109^{\circ} 15^{\prime} 05.6^{\prime \prime} \mathrm{E} \\
12^{\circ} 10^{\prime} 35.4^{\prime \prime} \mathrm{N}\end{array}$ & KY947257 & KY947273 \\
\hline MT16.2015 & $\begin{array}{c}\text { Spheciospongia } \\
\text { verparium }\end{array}$ & May-2015 & Nha Trang & $\begin{array}{l}109^{\circ} 15^{\prime} 05.6^{\prime \prime} \mathrm{E} \\
12^{\circ} 10^{\prime} 35.4^{\prime \prime} \mathrm{N}\end{array}$ & KY947258 & - \\
\hline
\end{tabular}


DNA extraction, PCR amplification of $18 S$ rRNA and COI genes

Sponge tissue $(500 \mathrm{mg})$ was used to extract genomic DNA using DNeasy Blood \& Tissue Kit (Qiagen, Germany) according to the manufacturer's protocol. The concentration of extracted DNA was measured by a Nanodrop 1000 spectrophotometer (Nanodrop Technologies, Wilmington, DE), and its integrity was examined by gel electrophoresis on agarose gel $1 \%(\mathrm{w} / \mathrm{v})$. The extracted DNA was dissolved in TE buffer and stored at () $20^{\circ} \mathrm{C}$ for further analysis.

The 18S rRNA genes $(\sim 1800 \mathrm{bp})$ and partial COI gene fragments $(\sim 650 \mathrm{bp})$ were amplified from extracted DNA using the primer pairs EukF/EukR (Medlin et al., 1988) and jgLCO1490/jgHCO2198 (Geller et al., 2013), respectively. The PCR products were cloned into the $\mathrm{pCR}^{\mathrm{TM}} 2.1$ vector (TA Cloning Kit, Invitrogen) according to the manufacturer's protocol. Positive clones were sequenced on DNA Analyzer (ABI PRISM 3100, Applied Bioscience).

\section{Construction of phylogenetic tree}

Sequences were trimmed to remove low-quality ends using Bioedit version 7.2.5. The vector contamination was removed using VecScreen (https://www.ncbi.nlm.nih.gov/tools/vecscreen/.

Forward and reverse 18S rRNA sequences were assembled to obtain near full-length fragments. Sequences in our study and the most their closely related sequences obtained from BLAST program (nr/nt) were aligned using Clustal W and Muscle algorithms on software MEGA 7.0 (Kumar et al., 2016). Phylogenetic trees for 18S rRNA and COI sequences were created using Maximum Likelihood (ML), Neighbor-joining (NJ), and Maximum parsimony (MP) with Kimura 2parameter model for ML and NJ, and Subtreepruning-regrafting (SPR) for MP using
MEGA7.0 (Kumar et al., 2016). The reliability of clades on the phylogenetic tree was assessed based on bootstrap values of 1000 replicates. Sequences were deposited in GenBank under accession numbers: KY947243-KY947258 (18S rRNA genes) and KY947259-KY947273 (COI genes).

\section{RESULTS AND DISCUSSION}

\section{Molecular taxonomy of sponges based on 18S rRNA gene}

The nearly full-length 18S rRNA gene fragments of all 16 sponge specimens were amplified successfully. The BLAST results showed that these 18S rRNA genes exhibited high similarity with other 18S rRNA sequences on NCBI (96.4-100\%) (Table 2). Results showed topology of phylogenetic trees using different methods was mostly agreement with slight difference in support value. The $18 \mathrm{~S}$ rRNA phylogenetic tree of collected samples showed phylogenetically diverse taxa of sponge specimens including 5 orders, 7 families, and 7 genera. Half of the samples were identified to species level based on their positions on the phylogenetic tree and their high similar level (> 99\%) to referred sequences (MT1.2015, MT7.2015, and MT10.2015 belonged to Amphimedon compressa; MT16.2015 belonged to Spheciospongia vesparium; MT3.2015, MT4.2015, and MT9.2015 belonged to Rhabdastrella globostellata). Although the $18 \mathrm{~S}$ rRNA sequences of other samples also had high similar level to those of reference sequences, they were only identified to genus level due to their positions on the phylogenetic tree were at the same branch with different species of the same genera (e.g., MT14.2015 and MT12.2015 in genus Tedania, MT6.2015, MT8.2015, and MT11.2015 in genus Clathria). Remaining samples (MT2, MT13, and MT15) were not identified to species level because of their low similarity (96.4-96.7\%) to referred sequences. 


\section{Molecular taxonomy of sponges based on COI gene}

The partial COI genes from 15 out of 16 sponge specimens were successfully amplified and sequenced. The PCR product of the sample MT16.2015 was very weak and was failed in sequencing. The COI gene sequences in our study displayed high similarity with other COI gene sequences on NCBI (99 $100 \%$ ) (Table 2). Constructions of the phylogenetic tree using different algorithms and methods indicated the topological agreement of phylogenetic trees (Fig. 2). Identification of the sponge specimens based on phylogenetic tree of COI genes also given similar results to identification based on the $18 \mathrm{~S}$ rRNA genes at genus level, except for MT5.2015 belonged to Tethyida and Axinellida clade. Fourteen out of $15 \mathrm{COI}$ genes could be identified to species level based on their positions on the phylogenetic tree and their high similar level (> 99\%) to referred sequences. The COI sequence of MT5.2015 could not be identified at a lower level (genus or species) because it was positioned at the same branch of two species belonging to two genera, Axos and Stelligera.

Table 2. The similarity of sequences in our study with reference sequences on NCBI

\begin{tabular}{|c|c|c|c|c|}
\hline \multirow[b]{2}{*}{ Code } & \multicolumn{2}{|l|}{ 18S rRNA } & \multicolumn{2}{|l|}{ COI } \\
\hline & Closely reference sequence & $\begin{array}{c}\text { Similarity } \\
(\%)\end{array}$ & Closely reference sequence & $\underset{(\%)}{\text { Similarity }}$ \\
\hline MT1.2015 & $\begin{array}{c}\text { Amphimedon compressa, } \\
\text { EU702409 }\end{array}$ & 99.9 & $\begin{array}{c}\text { Amphimedon compressa, } \\
\text { EU237474 }\end{array}$ & 99.3 \\
\hline MT2.2015 & Xestospongia muta, AY621510 & 96.4 & $\begin{array}{c}\text { Xestospongia testudinaria, } \\
\text { HQ452960 }\end{array}$ & 100 \\
\hline MT3.2015 & $\begin{array}{c}\text { Rhabdastrella globostellata, } \\
\text { KC } 902160\end{array}$ & 99.9 & $\begin{array}{c}\text { Rhabdastrella globostellata, } \\
\text { HM592673 }\end{array}$ & 99.8 \\
\hline MT4.2015 & $\begin{array}{c}\text { Rhabdastrella globostellata, } \\
\text { KC } 902160\end{array}$ & 99.9 & $\begin{array}{c}\text { Rhabdastrella globostellata, } \\
\text { HM592673 }\end{array}$ & 99.8 \\
\hline MT5.2015 & Axos cliftoni, EF654523 & 99.2 & Axos cliftoni, AY561974 & 99.4 \\
\hline MT6.2015 & Clathria reinwardti, KC902087 & 99.9 & Clathria reinwardti, HE611598 & 100 \\
\hline MT7.2015 & $\begin{array}{c}\text { Amphimedon compressa, } \\
\text { EU702409 }\end{array}$ & 99.8 & $\begin{array}{c}\text { Amphimedon compressa, } \\
\text { EU237474 }\end{array}$ & 98.7 \\
\hline MT8.2015 & Clathria reinwardti, KC902087 & 99.9 & Clathria reinwardti, HE611598 & 99.8 \\
\hline MT9.2015 & $\begin{array}{c}\text { Rhabdastrella globostellata, } \\
\text { KC } 902160\end{array}$ & 100 & $\begin{array}{c}\text { Rhabdastrella globostellata, } \\
\text { HM592673 }\end{array}$ & 99.8 \\
\hline $\begin{array}{c}\text { MT10.201 } \\
5 \\
\end{array}$ & $\begin{array}{c}\text { Amphimedon compressa, } \\
\text { EU702409 }\end{array}$ & 99.8 & $\begin{array}{c}\text { Amphimedon compressa, } \\
\text { EU237474 }\end{array}$ & 99.0 \\
\hline $\begin{array}{l}\text { MT11.201 } \\
5\end{array}$ & Clathria reinwardti, KC902087 & 99.9 & Clathria reinwardti, HE611598 & 99.8 \\
\hline \begin{tabular}{|l|} 
MT12.201 \\
5
\end{tabular} & Tedania ignis, AY737642 & 99.2 & Tedania ignis, DQ133896 & 99.8 \\
\hline \begin{tabular}{|l|} 
MT13.201 \\
5
\end{tabular} & Xestospongia muta, AY621510 & 96.7 & $\begin{array}{c}\text { Xestospongia testudinaria, } \\
\text { HQ452960 }\end{array}$ & 100 \\
\hline $\begin{array}{c}\text { MT14.201 } \\
5\end{array}$ & Tedania ignis, AY737642 & 99.4 & Tedania ignis, DQ133896 & 99.8 \\
\hline \begin{tabular}{|l|} 
MT15.201 \\
5
\end{tabular} & Xestospongia muta, AY621510 & 96.5 & $\begin{array}{c}\text { Xestospongia testudinaria, } \\
\text { HQ452960 }\end{array}$ & 100 \\
\hline $\begin{array}{l}\text { MT16.201 } \\
5\end{array}$ & $\begin{array}{c}\text { Spheciospongia vesparium, } \\
\text { AY734440 }\end{array}$ & 99.9 & - & - \\
\hline
\end{tabular}


The congruence of sponge classification based on 18S rRNA and COI gene

Phylogenetic trees of $18 \mathrm{~S}$ rRNA and COI genes indicated agreement of sponge taxonomy. At the genus level, the same genera were recovered based on two independent marker genes (18S and COI), except for specimen MT5.2015. Six out of 16 specimens showed also the agreement of taxonomy at the species level (MT1.2015, MT7.2015, MT10.2015 belonged to Amphimedon compressa, and MT4.2015, MT3.2015, MT9.2015 belonged to Rhabdastrella globostellata). Some specimens could not be identified at species level using individual marker; however, using a combination of both markers allowed to identify them at the species level. Specimens MT12.2015 and MT14.2015 (Tedania), and MT6.2015, MT8.2015, and MT11.2015 (Clathria) could not be identified to species level because the variation of 18S rRNA sequences between species in two genera Tedania and Clathria was very low. However, the COI phylogenetic tree of these specimens showed better resolution, and they could be identified to species level. In contrast, specimen MT5.2015 could not be identified to species level using only COI gene, however, this specimen could be identified to species level (Axos cliftoni) using 18S rRNA genes. In the case of specimens MT2.2015, MT13.2015, and MT15.2015, the 18S rRNA sequences showed low similarity with reference sequence on NCBI $(<98 \%)$, and could not be identified to species level because the 18S rRNA sequence of Xestospongia testudinaria was not available from NCBI. However, the COI sequences of these specimens showed $100 \%$ similarity with the COI sequence of Xestospongia testudinaria and could be identified as Xestospongia testudinaria.

The findings in our study are consistent with previous studies. The previous studies have suggested that low variation and slow evolution rate of 18S rRNA and COI genes may result in difficulty in identification of some sponges at the lower taxonomic level
(Duran et al., 2004; Redmond et al., 2007; Sipkema et al., 2003). For example, the $18 \mathrm{~S}$ rRNA sequences of two species belonging to two different genera (Amphimedon quenslandica and Haliclona (?gellius) sp.) are nearly identical (Sipkema et al., 2009) and unable to identification of these species using the 18S rRNA gene. Similarly, the COI sequences are often too conserved in sponges to resolve population-level relationships (Duran et al., 2004). However, the individual sequences display different evolution rates of sponges (Wang \& Lavrov, 2008) and may be more or less suitable for a specific classification. The mitochondrial sequences appear to evolve higher in some sponge taxa and have been used effectively for studies population level (Dailianis et al., 2011; Escobar et al., 2012) and detection of cryptic species (Andreakis et al., 2012; de Paula et al., 2012). These findings revealed that the individual markers often provide different rates of sponge evolution, combination of different phylogenetic markers, therefore, are expected to be more informative of sponge phylogeny at different levels.

At a higher classification level (orders), phylogenetic trees of 18S rRNA and COI sequences recovered the same clades; however, the branching order of clades in two phylogenetic trees was different. In addition, support value of nodes in $18 \mathrm{~S}$ rRNA phylogenetic tree was better than those in COI phylogenetic tree (Figs. 1 \& 2). The previously studies reveal that phylogenetic relationship of some orders (e.g., Haplosclerida) are different using 18S, 28S rRNA, and COI sequences (McCormack et al., 2002; Nichols, 2005). Morrow et al. (2012) also investigated the congruence of nuclear genes (18S and 28S rRNA) and mitochondrial gene (COI) in sponges (Demospongiae), and showed that the phylogenetic tree based on COI sequences recovered the same clades and same genera as the $18 \mathrm{~S}$ and $28 \mathrm{~S}$ rRNA tree. However, the branching order in the $\mathrm{COI}$ tree is different and less resolution than in 18S and 28S rRNA trees (Morrow et al., 2012). The difference may result from different evolution rate of 
$18 \mathrm{~S}$ rRNA and COI genes. For example, the evolution rate of mitochondrial sequences is higher than those of rRNA sequences for some orders such as Dictyoceratida and
Verticillitida. In contrast, the mitochondrial sequences display lower evolution rate than rRNA sequences for the order Homoclerophorida (Lavrov et al., 2008).

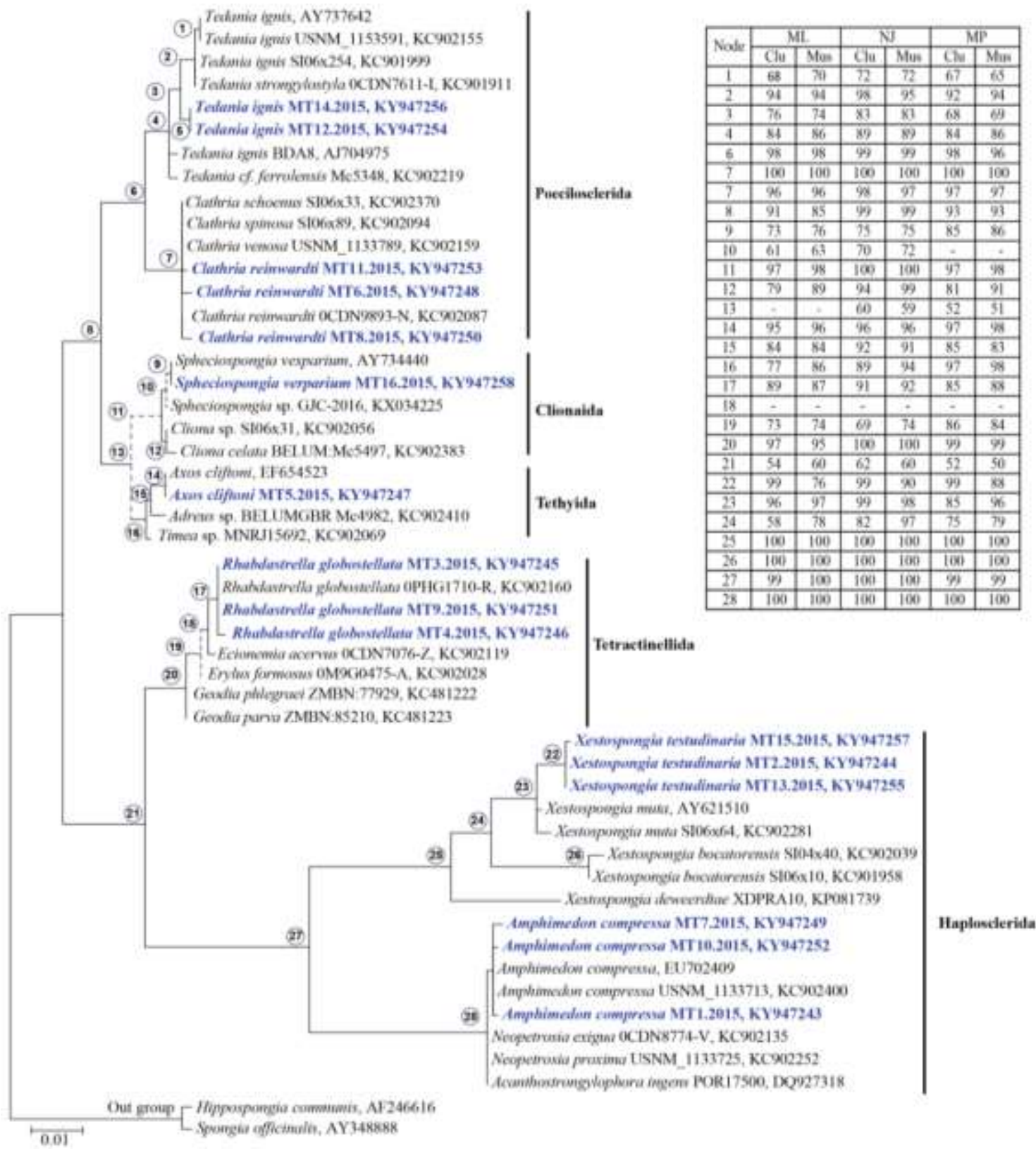

Figure 1. Phylogeny of $18 \mathrm{~S}$ rRNA gene sequences of sponges in our study (blue bold letters) and from NCBI. The tree topology was obtained from NJ. Individual bootstrap values from ML, NJ, MP with alignment methods ClustalW (Clu) and Muscle (Mus) are located in the upperright box and correspond to circled numbers on tree nodes. Solid lines indicate well-supported branches (support values greater than $50 \%$ for all criteria) and dashed lines indicate weakly supported branches 


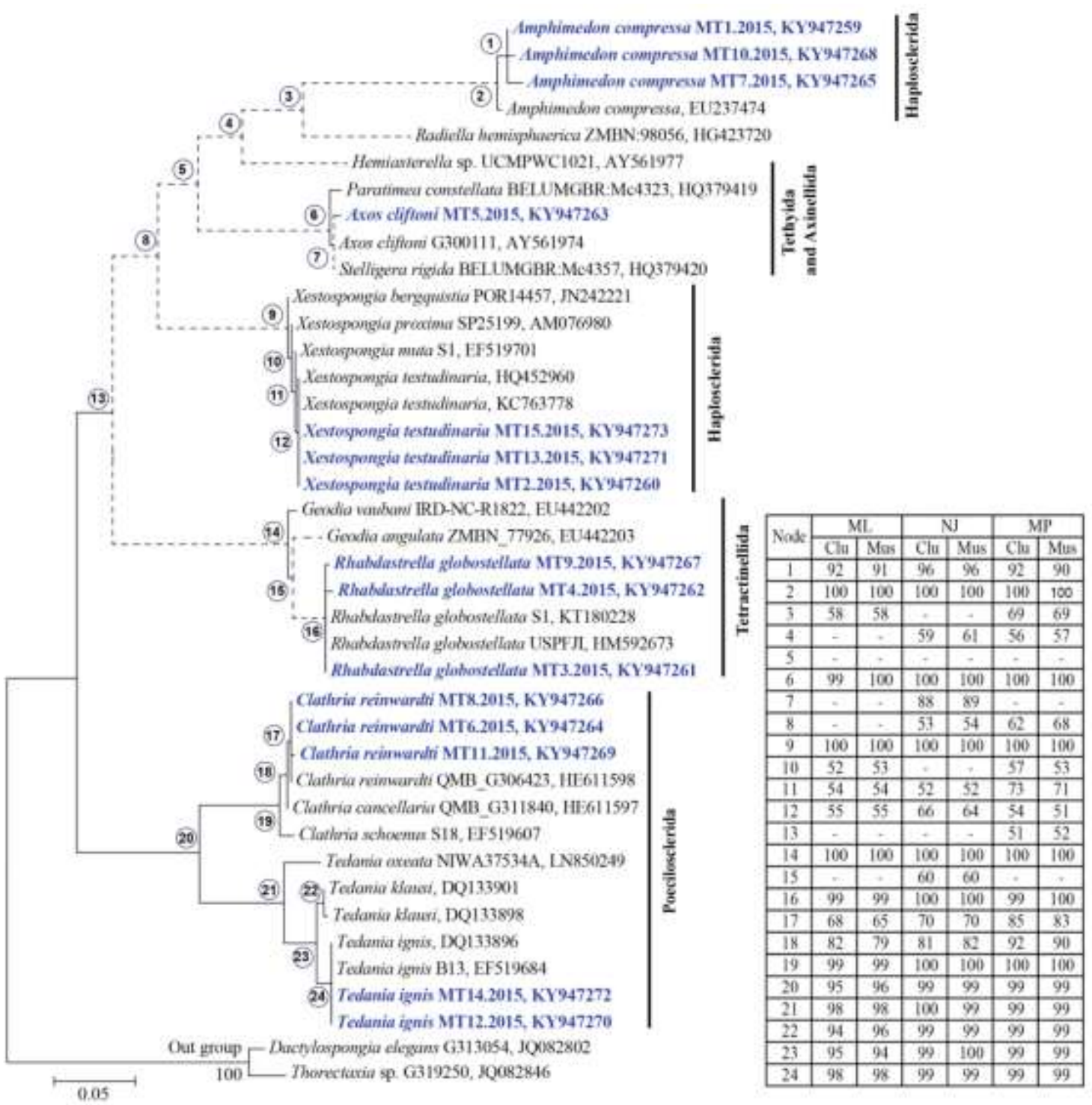

Figure 2. Phylogeny of partial COI gene sequences of sponges in our study (blue bold letters) and from NCBI. The tree topology was obtained from neighbor-joining (NJ) analysis. Individual bootstrap values from maximum likelihood (ML), NJ, maximum parsimony (MP) with alignment methods ClustalW (Clu) and Muscle (Mus) are located in the lower-right box and correspond to circled numbers on tree nodes. Solid lines indicate well-supported branches (support values greater than $50 \%$ for all criteria) and dashed lines indicate weakly supported branches.

\section{CONCLUSION}

Based on two molecular markers (18S rRNA and COI), sponges (Demospongiae) in Vietnam were identified. The obtained results showed the congruence of molecular taxonomy using two independent markers, however order of the clades in COI tree was different and less supported than from those in 18S rRNA. Combination of the two markers supported better for sponge identification. 
Acknowledgements: This work was supported by Vietnamese Ministry of Science and Technology under grant number: ĐTĐLCN.17/14."

\section{REFERENCES}

Andreakis N., Luter H. M., Webster N. S., 2012. Cryptic speciation and phylogeographic relationships in the elephant ear sponge Ianthella basta (Porifera, Ianthellidae) from northern Australia. Zool. J. Linn. Soc., 166(2): 225-235.

Bell J. J., 2008. The functional roles of marine sponges. Estuar. Coast. Shelf Sci., 79(3): 341-353.

Cárdenas P., Pérez T., Boury-Esnault N., 2012. Chapter two - Sponge Systematics Facing New Challenges, in: Mikel A. Becerro Manuel Maldonado and Xavier Turon BT - Advances in Marine Biology, M.J.U. (Ed.), Advances in Sponge Science: Phylogeny, Systematics, Ecology. Academic Press, pp. 79-209.

Dailianis T., Tsigenopoulos C. S., Dounas C., Voultsiadou E., 2011. Genetic diversity of the imperilled bath sponge Spongia officinalis Linnaeus, 1759 across the Mediterranean Sea: patterns of population differentiation and implications for taxonomy and conservation. Mol. Ecol., 20(18): 3757-3772.

de Paula T. S., Zilberberg C., Hajdu E., LôboHajdu G., 2012. Morphology and molecules on opposite sides of the diversity gradient: Four cryptic species of the Cliona celata (Porifera, Demospongiae) complex in South America revealed by mitochondrial and nuclear markers. Mol. Phylogenet. Evol., 62(1): 529-541.

Duran S., Pascual M., Turon X., 2004. Low levels of genetic variation in mtDNA sequences over the western Mediterranean and Atlantic range of the sponge Crambe crambe (Poecilosclerida). Mar. Biol., 144(1): 31-35.

Escobar D., Zea S., Sánchez J. A., 2012. Phylogenetic relationships among the Caribbean members of the Cliona viridis complex (Porifera, Demospongiae, Hadromerida) using nuclear and mitochondrial DNA sequences. Mol. Phylogenet. Evol., 64(2): 271-284.

Geller J., Meyer C., Parker M., Hawk H., 2013. Redesign of PCR primers for mitochondrial cytochrome c oxidase subunit I for marine invertebrates and application in all-taxa biotic surveys. Mol. Ecol. Resour., 13(5): 851-861.

Hooper J. N. A., Soest R. W. M., 2002. Systema Porifera: A guide to the classification of sponges. Kluwer Academic/Plenum Publishers, New York, pp. 1756.

Kumar S., Stecher G., Tamura K., 2016. MEGA7: Molecular Evolutionary Genetics Analysis Version 7.0 for Bigger Datasets. Mol. Biol. Evol., 33(7): 1870-1874.

Lavrov D. V, Wang X., Kelly M., 2008. Reconstructing ordinal relationships in the Demospongiae using mitochondrial genomic data. Mol. Phylogenet. Evol., 49(1): 111-124.

Maloof A. C., Rose C. V, Beach R., Samuels B. M., Calmet C. C., Erwin D. H., Poirier G. R., Yao N., Simons F. J., 2010. Possible animal-body fossils in preMarinoan limestones from South Australia. Nat. Geosci., 3: 653-659.

McCormack G. P., Erpenbeck D., van Soest R. W. M., 2002. Major discrepancy between phylogenetic hypotheses based on molecular and morphological criteria within the Order Haplosclerida (Phylum Porifera: Class Demospongiae). J. Zool. Syst. Evol. Res., 40(4): 237-240. 
Medlin L., Elwood H. J., Stickel S., Sogin M. L., 1988. The characterization of enzymatically amplified eukaryotic 16Slike rRNA-coding regions. Gene, 71(2): 491-499.

Morrow C. C., Picton B. E., Erpenbeck D., Boury-Esnault N., Maggs C. A., Allcock A. L., 2012. Congruence between nuclear and mitochondrial genes in Demospongiae: A new hypothesis for relationships within the G4 clade (Porifera: Demospongiae). Mol. Phylogenet. Evol., 62(1): 174-190.

Nichols S. A., 2005. An evaluation of support for order-level monophyly and interrelationships within the class Demospongiae using partial data from the large subunit rDNA and cytochrome oxidase subunit I. Mol. Phylogenet. Evol., 34(1): 81-96.

Quang T. M., 2013. A review of the diversity of sponges (Porifera) in Vietnam, in: The Proceedings of the 2nd International
Workshop on Marine Bioresources of Vietnam. Ha Noi, Vietnam, pp. 109-115.

Redmond N. E., van Soest R. W. M., Kelly M., Raleigh J., Travers S. A. A., McCormack G. P., 2007. Reassessment of the classification of the Order Haplosclerida (Class Demospongiae, Phylum Porifera) using 18S rRNA gene sequence data. Mol. Phylogenet. Evol., 43(1): 344-352.

Sipkema D., Heilig H. G. H. J., Akkermans A. D. L., Osinga R., Onji J., Wijffels R. H., 2003. Sponge-Cell Culture? A Molecular Identification Method for Sponge. Cells. Mar. Biotechnol., 5(5): 443-449.

Sipkema D., Holmes B., Nichols S. A., Blanch H. W., 2009. Biological Characterisation of Haliclona (?gellius) sp.: $\quad$ Sponge and Associated Microorganisms. Microb. Ecol., 58(4): 903-920. 
